\title{
Modelo en desorden: Estado de bienestar, dogmatismo de austeridad y cambio radical en las políticas de migración suecas
}

\author{
Model in disarray: welfare, austerity dogmatism \\ and the u-turn in Swedish migration politics
}

Carl-Ulrik Schierup*

ISSN IMPRESO 1870-7599 | ISSN RED CÓMPUTO 2448-7783 | 71-104

Simone Scarpa**

\begin{abstract}
Resumen. La sombra de xenofobia que se cierne sobre Europa ha arrojado al cubo de basura los fundamentos morales de una política inclusiva de migración en Suecia y ha tergiversado un consenso de izquierda y derecha sobre una política de asilo abierta y humanitaria hacia su extremo opuesto. Desde el 2015, atraídos por los avances de la extrema derecha, los principales partidos políticos han aceptado indistintamente que la inmigración, la diversidad etnocultural y la política de puertas abiertas para refugiados van en perjuicio del Estado de bienestary, como consecuencia, frenar la migración se ha convertido en la estratagema política dominante para la obtención de votos. Los autores desafían esta narrativa ampliamente aceptada al argumentar que la sostenibilidad del Estado de bienestar en Suecia no ha sido socavada a causa de la migración sino a la firme adherencia hacia políticas de austeridad por consecutivas gubernaturas suecas desde comienzos de los 1990. Las políticas de austeridad han debilitado, poco a poco, las funciones socialmente integradoras del Modelo Sueco y han impedido la implementación de una agenda ambiciosa que reúna una interacción potencialmente dinámica de políticas económicas y sociales expansionistas, así como una política de asilo humanitaria.
\end{abstract}

Palabras clave: Modelo Sueco, Estado de bienestar, políticas migratorias, solidaridad social.

\begin{abstract}
The winds of xenophobia hovering over Europe have swept the moral political foundations of an inclusive Swedish migration policy into the dustbin of history and twisted an enlightened left-right consensus on an open and humanitarian asylum policy into its mirror opposite. Lured by advances of the extreme right the main political parties have, since 2015 , come to indiscriminately embrace the view that immigration, etno-cultural diversity and an open-door refugee policy is detrimental to welfare and, in consequence, curbing migration has become the all dominant political strategem in vying for votes. The authors challenge this widely accepted narrative by arguing that the sustainability of the Swedish welfare state has not been undermined by migration but by consecutive Swedish governments' unbending adherence to austerity politics since the beginning of the 1990s. Austerity politics have, step by step, weakened the Swedish Model's socially integrative functions and prevented the implementation of an ambitious agenda, harvesting a potentially dynamic interplay of expansionary economic and social policies and a humanitarian asylum policy.
\end{abstract}

Keywords: Swedish Model, welfare state, migration policies, social solidarity.

*Profesor de la Universidad de Linköping, Suecia.

**Profesor y conferenciante de la Universidad de Umeå, Suecia.

Traducido del inglés por Diana Laura Ibarra Rodríguez y Georgia Aralú González Pérez. 


\section{¿La migración es negativa para el Estado de bienestar?}

Una de las intervenciones más influyentes es el debate en curso sobre migración y Estado de bienestar, que se encuentra en el estudio comparativo sobre la lucha contra la pobreza en Estados Unidos y Europa de los economistas Alberto Alesina y Edward Glaeser (2004). Predicen que, a largo plazo, la creciente inmigración forzará a los países europeos a reducir el apoyo del Estado de bienestar al recortar el gasto público y así avanzar hacia el modelo de bienestar residual de Estados Unidos. Una premisa de su argumento es que la inmigración a gran escala y la diversidad étnica (concomitante) pueden llegar a ser perjudiciales para la construcción de la solidaridad colectiva al socavar la voluntad de los ciudadanos (y de la clase trabajadora, en particular) de financiar programas integrales de bienestar social. Es un discurso controversial que ha circulado ampliamente en Economía (véase Stichnoth y Van der Straeten, 2013) y otras ciencias sociales (véase Eger, 2010; Larsen, 2011; Dahlberg et al., 2012; Finseraas, 2012; Lentin y Titley, 2011; Hooijer y Picot, 2015; Koopmans, 2010). Sin embargo, ha sido discutido radicalmente (véase Wagle, 2013) por cuestionar la base de sus argumentos teóricos y analíticos, y poner en duda la validez de su evidencia empírica. TaylorGooby (2005), basado en los resultados de un estudio internacional exhaustivo, expone que el presunto efecto negativo de la diversidad etnorracial en la solidaridad colectiva y el gasto público se reduce a Estados Unidos.

Kymlicka y Banting (2006) sostienen que la diversidad etnorracial y la alta migración, sean o no causas de detrimento en el gasto social, están políticamente determinadas. Las políticas combatientes del estigma social que acompañan a los migrantes y a las minorías raciales incrementan la motivación colectiva para la solidaridad social y la construcción nacional. De complementaria manera, Mau y Bukhardt (2007) manifiestan que los valores y actitudes públicas no sólo son actos que reflejan el grado de fraccionamiento etnorracial, ni el nivel de inmigración en un país. Los valores y actitudes son mediados por las estructuras del Estado benefactor; dependen de cómo se organiza la inclusión y exclusión institucionalmente, y si los programas de política social han sido construidos de forma que fortalezcan o debiliten los conflictos sobre la redistribución. ${ }^{1}$ La idea principal de que la creciente

${ }^{1}$ En otros trabajos hemos discutido a profundidad estas controversias y proposiciones relativas al caso sueco (Scarpa, 2015b). 
diversidad étnica causada por la inmigración tiende a menoscabar el apoyo para el Estado de bienestar y a limitar la magnitud real de la redistribución que puede lograrse en un país, continúa siendo de gran alcance.

Desde hace mucho tiempo, la aludida diversidad étnica ha sido considerada por varios de los partidos europeos de extrema derecha, entre ellos, el Front National en Francia y los partidos nórdicos, incluyendo al Partido Demócrata Sueco (Sverigedemokraterna). En adición, ha impulsado la formación de una hegemonía neoliberal-neoconservadora contemporánea a través de la corriente política europea, lo que posiblemente repercutirá en el desarrollo del futuro de Europa. En ese sentido, es pertinente seguir sometiendo la supuesta ecuación negativa entre diversidad e igualdad al escrutinio teórico y empírico.

Una oposición oximorónica entre inmigración y Estado de bienestar se concibe como evidencia irrefutable de que la inmigración debe ser condenada. La diversidad étnica, fruto de este fenómeno, debilitará la solidaridad nacional. Deben prevalecer ciertas reglas, puesto que existen inmigrantes dentro de los límites de la frontera. Los ciudadanos «nativos» deben ser tratados de modo distinto que los «no nativos», con el fin de proteger los intereses de los primeros ante los escasos recursos del Estado de bienestar plagado de crisis dentro de un endurecido mundo globalizado. Estos son los axiomas populistas que colonizaron gran parte del espectro político sueco desde la derecha hasta la centro-izquierda.

Después de haber sido un país con altos niveles de emigración a principios del siglo XIX, Suecia se convirtió en uno de los más importantes respecto a la inmigración en el Atlántico Norte posterior a la Segunda Guerra Mundial. En la actualidad es uno de los países miembro de la Organización para la Cooperación y el Desarrollo Económicos (OCDE) con la mayor proporción de extranjeros nacidos dentro de su población (16 por ciento o 1.6 millones sobre un total de 10 millones de habitantes). Alrededor de 30 por ciento de todos los niños nacidos en Suecia tiene uno o ambos padres extranjeros (Raneke, 2013). Por consiguiente, la inmigración es una de las principales razones por las que el país experimenta una inminente crisis "demográfica», en menor grado comparado con otros países europeos; además ha contribuido y sigue contribuyendo enormemente al crecimiento económico de Suecia (Scocco y Andersson, 2015).

Las premisas fundamentales de la política de inmigración sueca fueron formuladas a mediados de 1970 durante el apogeo del Modelo Sueco, el cual pertenece al Estado de bienestar socialdemócrata. A pesar de las paradojas, siempre presentes, que a menudo se basan en discrepancias alarmantes entre 
teoría y práctica (Ålund y Schierup, 1991), durante mucho tiempo el modelo enfrentó positivamente - comparado con la mayoría de los países europeos - el desafío de fusionar los derechos civiles, políticos y sociales de la ciudadanía con un marco político separado de las concepciones "nativistas» de "pertenencia» (Ryner, 2000:68). Esto ha dependido del sostenimiento de un amplio consenso de principios, respaldado por todos los partidos políticos dominantes de izquierda y de derecha, para no explotar los temas de migración, etnicidad, raza o nación como estratagemas políticas populistas. Se trata de un consenso destinado a una política de asilo liberal, acerca de normas liberales encaminadas a la unificación familiar, al acceso rápido para la obtención de la residencia permanente y la ciudadanía completa, y la importancia de apoyar el empoderamiento político de los migrantes y sus descendientes. Dicho consenso ha sido cuestionado en repetidas ocasiones y parcialmente restaurado en el contexto de las crisis recurrentes y las reformas del Modelo Sueco (Allund y Schierup, 1991; Schierup y Ålund, 2011b). No obstante, con la sombra de la xenofobia y el neofascismo cerniéndose sobre la actual Europa y Suecia, hemos visto el desecho autorizado de los cimientos morales y políticos del Modelo Sueco original; hemos experimentado también la transmogrificación de un consenso aún predominante en su extremo opuesto.

En seguida, rescatamos una explicación histórica-estructural de esta volte face con enfoque en la transformación a profundidad de la economía política y los apoyos institucionales del llamado Modelo Sueco del Estado de bienestar durante su «época de oro», con el objetivo de describir el desmantelamiento sistemático, a inicios de los 1990, de los pilares que lo sostienen. Después nos centramos en el cambio de un expansivo Estado de bienestar keynesiano, con el pleno empleo como principal prioridad, a un modelo neoliberal impulsado por la austeridad, que subordina las políticas sociales y de empleo a los objetivos de control de inflación y reducción de la deuda. Argumentamos consecuencias de la creciente inequidad y exclusión social con un enfoque en el Estado de bienestar sueco, así como su migración contingente y políticas de integración. Planteamos la cuestión de posibles futuros alternativos que lleven más allá de la actual lucha por la hegemonía política, donde el xenorracismo populista es el actor principal. En esta batalla, la estratagema crucial es quien ejercerá el poder para llenar de legitimidad el significante fluctuante de solidaridad. 


\section{El Modelo Sueco}

Generalmente, Suecia es reconocida como el ejemplo ideal del Estado de bienestar universalista. El amplio periodo de hegemonía política del Partido Sueco Socialdemócrata (Sveriges Socialdemokratiska Arbetareparti, de ahora en adelante SAP), puede ser considerado como el primer pilar del modelo. De manera tradicional, la fuerza política del SAP residió en «movimientos populares» de clase (folkrörelser), los cuales se centraban en sindicatos sólidos con altas tasas de afiliación. Dentro de un contexto de estabilidad política de larga duración el SAP fungió como garante en cuanto a los derechos laborales y además se valió de su plena dominación para establecer una fuerte regulación colectiva de pago y condiciones de empleo, así como el derecho a la cogestión en el lugar de trabajo.

La socialdemocracia logró mantener su hegemonía al formar alianzas con objetivos comunes de política social. Por ende, el Modelo Sueco original derivado de principios de los 1930 se apoyó en dos grandes pactos históricos: el denominado Cow Deal (Kohandeln) en 1933 entre el SAP y la Liga de Campesinos (Bondeförbundet), que representaba a pequeños campesinos, y el importante acuerdo Saltsjöbaden (Saltsjöbadsavtalet) en 1938 entre la Confederación Sindical Sueca y la Federación de Empresarios.

El segundo pilar del Modelo Sueco puede identificarse en el presunto Modelo Rehn-Meidner (Rehn-Meidner Modellen), una teoría para la economía política de un Estado de bienestar igualitario y dinámico, insertada en las décadas de 1950 y 1960. Dicha teoría se estableció bajo la combinación de un compromiso al pleno empleo, una política salarial «solidaria» y una restrictiva política fiscal. Históricamente, Suecia ha tenido uno de los más altos grados de centralización en negociaciones salariales, las cuales a su vez han hecho posible la implementación de una política salarial solidaria, en la que los trabajadores continúen comprometidos con la modelación salarial, es decir, recibir el mismo pago por un mismo trabajo, independiente de la rentabilidad de sus empresas. Derivado de esta solidaria política se obtuvo la fuerte compresión de la estructura salarial, que aseguró uno de los más bajos niveles de inequidad en ingresos dentro del área de la OCDE (Rueda y Pontusson, 2000). Otra consecuencia fue la creación de un ambiente económico dinámico, en el que la elevación de salarios en empresas menos competitivas desembocó en cierres y quiebres, pero también en un mejoramiento continuo de la estructura industrial. Paralelamente, la moderación salarial garantizó grandes ganancias en empresas más competitivas y de carácter exportador. La meta de la 
política laboral activa fue asegurar empleo pleno, mediante la capacitación y la mejora de trabajadores desplazados en empresas menos competitivas, y alentar la recontratación en otras más competitivas ubicadas en diversas zonas geográficas (Scarpa, 2013). Así, la prioridad del modelo Rehn-Meidner fue mantener el desempleo al mínimo y garantizar el pleno empleo.

El tercer pilar del Modelo Sueco fue el principio del universalismo del Estado de bienestar; una política social generosa y global que sirvió como instrumento para generar lealtad al Modelo Sueco entre las clases y, así, proteger al Estado de bienestar contra «sentimientos reaccionarios» (Esping-Andersen, 1990:69).

Tradicionalmente, la cobertura total de los seguros sociales se ha sostenido gracias a los derechos básicos de seguridad y a las prestaciones complementarias relacionadas con el salario. Dichos derechos se ofrecieron a todos los ciudadanos con el objetivo de erradicar la pobreza, además se agregaron medidas salariales con una función de mantenimiento de los ingresos para salvaguardar el nivel de vida en caso de interrupción de empleo. Esa estructura bipartita contempla en general a los grupos sociales inmersos en los mismos programas del Estado de bienestar, con el fin de conformar una amplia coalición pro bienestar entre trabajadores y una creciente clase media de profesionales ejecutivos de trabajadores de cuello blanco (Esping-Andersen, 1990:67-69).

En adición, el Estado de bienestar universalista necesita el desarrollo de una gran infraestructura de servicios sociales, capaz de absorber una parte sustancial de la mano de obra. La creación de tales trabajos en el Estado de bienestar, en conjunto con el sistema de negociación centralizado, ha provocado la supresión de la segmentación en el mercado laboral sueco (Swenson, 1991); es decir, la abolición de las distinciones entre sectores de empleo primarios y secundarios, cada uno con su propia paga y condiciones de trabajo. De igual modo, brindar servicios públicos de bienestar integral comprende todos los niveles de educación, cuidado de niños y ancianos, servicios de salud, etcétera, dirigidos a los grupos profesionales, tanto tradicionales como nuevos, de clase media.

La base social y la legitimidad pública del Estado de bienestar se fortalecieron por la incorporación a gran escala de la mujer en el mercado laboral; aunque su inclusión en el sistema de bienestar en igualdad de condiciones no fue sustancial al menos fue formal. Por otro lado, el sistema de servicios sociales públicos debía 
sustituir su trabajo doméstico. ${ }^{2}$ Asimismo, durante el periodo de 1960 a 1970, los trabajadores inmigrantes en Suecia fueron incorporados bajo el término de «inclusión subordinada» (Mulinari y Neergaard, 2005). Los trabajadores migrantes, que se encargarían del auge de los ciclos económicos y la escasez temporal de mano de obra, con frecuencia fueron discriminados (Rauhut, 2010); y fue de este modo que surgió la división étnica laboral (Persson, 1972; Ålund, 1985; Schierup y Paulson, 1994). Sin embargo, los migrantes no fueron explotados como trabajadores extranjeros desechables sin derechos básicos de ciudadanía o como trabajadores clandestinos sometidos a un mercado laboral irregular, a diferencia de Europa central y meridional. Pronto se les reconoció como residentes permanentes, disfrutando (no siempre en la práctica) de pleno acceso al sistema de bienestar (véase Hammar, 1990). A mediados de la década de 1970, un conjunto de medidas jurídico-institucionales socialmente inclusivas resumía las intenciones de la política sueca de inmigración e integración a través de la fórmula «igualdad, el derecho a la diversidad y a la participación» (Ålund y Schierup, 1991).

Lo anterior garantizaría el acceso incondicional al conjunto de derechos de ciudadanía dentro del avanzado Estado de bienestar sueco. Cabe agregar que se restituyeron vías rápidas a permisos de residencia permanente, naturalización y unificación familiar con el propósito de facilitar la participación y el empoderamiento de los migrantes. En un inicio, se respetaron los derechos para retener y movilizar los recursos únicos de cultura e identidad de los migrantes y sus descendientes (Ålund y Schierup, 1991; Schierupy Ålund, 2011a, capítulo 1). El interés de este estudio se centra en la casi completa incorporación de trabajadores migrantes como miembros de organizaciones sindicales y, por medio de éstos, hacia el sistema de negociación colectiva. Ello, aunado a la migración regulada y al proceso ordenado para el asilo e integración de refugiados dentro del mercado laboral y el sistema de relaciones industriales, significaba la prevención de la explotación salarial, con la finalidad de combatir la segmentación etnorracial y salvaguardar la solidaridad al interior de la clase obrera. Eso se complementó con la política de residencia permanente como su piedra angular, a la par del rápido acceso a la ciudadanía plena, hecho que se considera prioritario en la rápida incorporación social y laboral.

${ }^{2}$ A pesar de la alta tasa de empleo femenino, el mercado laboral sueco se ha mantenido como uno de los más segregados en cuestión de género en Europa (EGGE, 2009). 


\section{Hacia una «consolidación de Estado» neoliberal}

A mediados de los 1980, el segundo pilar del Modelo Sueco, esto es, el modelo Rehn-Meidner, comenzó a enfrentar problemas de tipo estructural debido a la constante fragmentación de estructuras de negociación colectiva, lo que condujo hacia una dispersión sectorial de crecimiento salarial y a aumentos superiores a la media en la mayoría de las empresas competitivas orientadas a la exportación (Ryner, 2002). La disminución de la coordinación en las negociaciones salariales provocó un aumento de las tasas de inflación, mientras que la liberalización de crédito contribuyó al auge del consumo, financiado en gran medida a través de préstamos de mercados financieros internacionales (Englund, 1999). El sobrecalentamiento de la economía nacional se agravó como consecuencia de la decisión del gobierno central por mantener los tipos de interés elevados para defender la corona sueca, y adoptó un tipo de cambio fijo asociado a la unidad monetaria europea (ECU). El país se vio obligado a efectuar una devaluación para evitar los ataques especulativos contra la (sobrevaluada) moneda nacional. A raíz de eso, el sistema bancario estuvo bajo presión a causa del aumento de costes en la amortización de los préstamos exteriores. La crisis del sector bancario creció rápidamente hasta convertirse en una crisis financiera de gran alcance en todos los sectores de la economía, con una caída impresionante del PIB y un número significativo de bancarrotas.

El estallido de la crisis financiera se asoció también con la aparente caída del primer pilar del Modelo Sueco, es decir, la hegemonía política del SAP. Las fechas simbólicas de este declive se identifican por los resultados de las elecciones nacionales en 1991 y, recientemente, por las de 2006 y 2010, en las que ganó una alianza conformada por cuatro partidos de centro-derecha. Ello interrumpió un periodo de gobierno socialdemócrata que de otro modo sería estable. ${ }^{3}$ Sin embargo, las cuentas más actuales sugieren que en Suecia y en otros países europeos, el apoyo a la socialdemocracia entró en crisis desde tiempo atrás, además su hegemonía prevaleció hasta finales de 1960. En opinión de Andersson, «el periodo posterior ha sido una creciente competencia electoral e incertidumbre política, no sólo caracterizada por la dependencia de la socialdemocracia hacia las alianzas, sino además por las tensiones que han ido en aumento dentro del mismo movimiento

${ }^{3}$ Con el apoyo condicionado del Partido de la Izquierda Sueca (Vänsterpartiet), heredero del antiguo partido comunista sueco. 
obrero» (2015:568). Para la década de 1990, la política sindical anteriormente unificada y el sistema centralizado de negociación salarial fueron desmantelados a favor de la negociación descentralizada y los convenios colectivos entre sindicatos y empleadores en el nivel de sucursal y empresa.

La crisis financiera que sobrevino en el corto gobierno centro-derechista (1991-1994) de Bildt suele verse como la llave que abrió las puertas a un régimen de austeridad neoliberal. ${ }^{4}$ Empero, en su plan financiero para 1989-1990, el gobierno socialdemócrata de ese entonces había desechado la política macroeconómica keynesiana con el fin de seguir las prescripciones políticas neoliberales (Ryner, 2002). Un nuevo gobierno socialdemócrata, que dominó desde 1994 hasta 2006, compartió premisas ideológicas con el Nuevo Laborismo Británico y su Tercera Vía, incluso continuó subordinando sus reiteradas promesas de garantizar el pleno empleo, como parte de las medidas contra la inflación. Lo anterior contribuyó para situar a Suecia entre los países de la OCDE con el más rápido crecimiento en desigualdad de ingresos. Si bien partió de un nivel muy bajo (Björklund y Jäntti, 2011), revirtió de ese modo una tendencia ininterrumpida de decenios de disminución de la desigualdad. Un nuevo Modelo Sueco emergente se aproximaba a los ideales del arraigado neoliberalismo prescrito por las actuales políticas de la Unión Europea, que a la vez compartía sus riesgos sociales inherentes; en otras palabras, un programa transformador, pero en peligro inminente de vender la ciudadanía social y la justicia distributiva.

A principios de los 1990, la crisis financiera provocó que el desempleo se disparara a niveles nunca antes vistos desde la década de 1930. La tasa global aumentó de manera abrupta de 1.5 por ciento en 1989 a 8.1 por ciento en 1994. El aumento de los costos del sistema de prestaciones sociales, aunado a la caída de ingresos fiscales, obligó al gobierno central a adoptar medidas de contención de los costos, puesto que la deuda pública casi se duplicó, de 45 por ciento del PIB en 1990 a más de 80 por ciento en 1995 (Haffert y Mehrtens, 2015:134). En última instancia, la crisis financiera dio lugar al comienzo de la fase de reducción del Estado de bienestar sueco y, por tanto, al debilitamiento del tercer pilar del modelo Estado sueco, es decir, el principio del universalismo.

En general, esta crisis financiera se reconoce como el acontecimiento que desencadenó la contracción del Estado de bienestar en Suecia. Aunque su dramático impacto en la economía es innegable, no especifica por qué no se invirtió el

\footnotetext{
${ }^{4}$ Véase la discusión detallada en Schierup et al. (2006).
} 
proceso de recesión cuando mejoró la economía y un nuevo gobierno socialdemócrata asumió el poder desde mediados de los 1990 hasta 2006.

Una posible explicación proviene de las teorías sociales que relacionan la reducción de la autonomía financiera de los gobiernos nacionales a las presiones derivadas de la integración europea y, en consecuencia, de la imposición de la austeridad como política macroeconómica por «defecto». Wolfgang Streeck (2014), por ejemplo, ha descrito el papel de la Unión Europea como una «máquina de liberalización» que, al imponer la flexibilización, la desregulación y la privatización a los Estados miembros, redujo de forma constante pero irrevocable la capacidad de los gobiernos nacionales para intervenir en la economía e invertir en las instituciones del Estado de bienestar.

El punto final de dicho proceso de reestructuración fue lo que Streeck definió como el Estado de «consolidación», es decir, un régimen de gobernanza multinivel dedicado a continuar con la política de austeridad, basado en un doble proceso de «despolitización de la economía» y de «desdemocratización de la política». El estado de consolidación es una antítesis del Estado de bienestar keynesiano. Surgió como respuesta al desplazamiento del equilibrio de poder hacia los mercados financieros, que se han convertido en la circunscripción política más poderosa de los Estados miembros de la Unión Europea.

Las medidas de consolidación fiscal, basadas en la autoridad, funcionan como instrumentos a través de los cuales los gobiernos de los Estados de consolidación demuestran su voluntad de responder a las expectativas de los mercados financieros, en detrimento de otros actores políticos, representados por el movimiento sindical y las organizaciones de la sociedad civil. La fútil esperanza de los gobiernos a cargo de los Estados de consolidación es que, al "ganar tiempo» con medidas de austeridad (Streeck, 2014), puedan eventualmente reintroducir políticas expansivas y de demanda que conduzcan a un crecimiento económico sostenido, a un aumento del empleo y a una disminución de la desigualdad social.

\section{Sanciones de un dogmatismo naturalizado}

El ejemplo sueco muestra que esta expectativa no se materializó cuando la economía se recuperó de la recesión y se convirtió en una de las de mayor crecimiento en Europa, a pesar de que el pacto de austeridad fiscal de la eurozona no es vinculante para Suecia como país no miembro. En un estudio reciente, 
Haffert y Mehrtens (2015) indicaron que la adopción de un régimen fiscal austero en Suecia, tras la crisis de principios de los 1990, reorientó el debate sobre la política fiscal hacia un consenso amplio y arraigado en torno de la necesidad de mantener el gasto público bajo control: «Todos los partidos se esfuerzan por evitar la impresión de que se comportan de manera irresponsable desde el punto de vista financiero. El gobierno y la oposición se están superando en una carrera para ver quién puede gastar menos dinero público» (Haffert y Mehrtens, 2015:136). Dicho reajuste entre partidos a favor de la austeridad fue el resultado de la introducción de estabilizadores fiscales automáticos en 1997, que han obligado al gobierno central a mantener un objetivo de superávit presupuestario de 1 por ciento del PIB en cada ciclo económico con el fin de reducir la deuda pública acumulada. Desde ese año, los gobiernos suecos se han visto obligados en la práctica a cumplir este objetivo y a evitar déficits, a la vez que mantienen la inflación baja. La introducción de un tope de gastos (también a partir de 1997) ha reducido drásticamente el margen de maniobra de las políticas expansivas en favor del bienestar, no obstante que los excedentes presupuestarios pueden seguir utilizándose para recortar los impuestos «ya que el tope afecta a los gastos pero no a los ingresos» (Haffert y Mehrtens, 2015:137). Paralelamente, los recortes tributarios financiados con excedentes han generado presiones para recortes adicionales en el gasto social, junto con una restricción general del gasto del sector público.

En 1998, el déficit presupuestario anterior se convirtió en un superávit presupuestario, caso que continúa vigente; sin embargo, ninguno de los principales partidos políticos ha cuestionado públicamente la búsqueda de la autonomía, tampoco ha intentado modificar el marco general de control del gasto público, ni siquiera marginalmente. En consecuencia, uno de los resultados más visibles de la transformación del Modelo Sueco de un Estado de bienestar completamente institucionalizado es «el caso más avanzado de un Estado de consolidación con un régimen de austeridad firmemente establecido» (Streeck, 2015:23), mismo que ha significado un fuerte descenso de los ingresos y el gasto público. La disminución tanto del gasto como de los ingresos públicos fue de aproximadamente 10 puntos porcentuales del PIB entre 1990 y 2012, aunque el primero disminuyó más rápidamente que el segundo, hecho que aseguró los superávit presupuestarios necesarios (Haffert y Mehrtens, 2015:139). Los recortes en el gasto público condujeron a varios tipos de ajustes en el Estado de bienestar sueco, incluyendo los ámbitos políticos y todos los tipos de prestación de servicios e ingresos. Así, una investigación oficial dirigida al Parlamento sueco por un grupo de destacados analistas políticos, 
demostró que desde principios de los 1990 Suecia perdió liderazgo en cuanto a la relativa generosidad de diversas prestaciones sociales en comparación con otros países de la OCDE (Palme, Ferrarini, Sjöberg y Nelson, 2012).

Concretamente, el sistema de seguro de desempleo ha sido objeto de importantes reformas con respecto a la financiación y a las prestaciones. Dichas reformas concernían al nivel de sustitución de las prestaciones y otros niveles máximos de ingresos para la sustitución, así como a los costes de las cuotas de afiliación. El estudio citado estimó que hasta 2005 el sistema sueco de seguro de desempleo era el segundo más generoso de la OCDE (después de Suiza); no obstante, en un periodo de cinco años hasta 2010, el importe medio de las prestaciones era inferior al de 12 países comparables (Palme, Ferrarini, Sjöberg y Nelson, 2012:32). La disminución de la tasa de reemplazo en 2007 fue en parte responsable de esta reducción en las prestaciones. Una razón más se relaciona con la decisión implícita de no ajustar el nivel máximo de renta a la inflación y a la evolución de los salarios desde 2002 (Inspektionen för Socialförsäkringen, 2013). Mientras que en ese año 80 por ciento de los trabajadores de tiempo completo (elegibles) que perdió su empleo recibió beneficios equivalentes a la tasa de reemplazo legislada, esa proporción disminuyó a 10 por ciento en 2015 (Arbetslöshetskassornas Samorganisation, 2015). Ello puede explicarse si se toma en cuenta que las cuotas de afiliación de los fondos de seguro de desempleo controlados por los sindicatos eran extremadamente bajas hasta 2007 y eran además deducibles de impuestos. Ese año, el gobierno de derecha decidió desplazar una parte mayor de la carga financiera del sistema de seguro de desempleo de los impuestos generales a los fondos controlados por los sindicatos y, de esa manera, abolir las deducciones fiscales sobre las cuotas de afiliación. El efecto de la reforma provocó un aumento general de las cuotas de afiliación individuales, lo que condujo a unas 400 mil personas a abandonar los fondos de desempleo y a unos 250 mil trabajadores a abandonar los sindicatos (Kjellberg, 2011:90). La disminución de la afiliación sindical fue muy amplia en los sectores de empleo con la mayor proporción de trabajadores nacidos en el extranjero (Kjellberg, 2011:84).

En última instancia, la reducción de la afiliación a la Caja del Seguro de Desempleo se tradujo en un aumento paralelo de las personas no afiliadas sin derecho a las prestaciones de desempleo (fundadas en el seguro), quienes se vieron obligadas a recurrir a la asistencia social municipal. Las reformas del sistema de seguro de enfermedad, impulsadas por la austeridad, han sido otro factor que ha contribuido al aumento del número de casos de asistencia social. En resumen, la 
asistencia social pasó de ser el último recurso de seguridad de ingresos para las personas que experimentan dificultades económicas temporales a ser «una fuente permanente de ingresos en circunstancias en las que el desempleo y el seguro de enfermedad cubren a las personas de manera cada vez más insuficiente» (Angelin, Johansson y Koch, 2014:173). Con todo, el aumento de la importancia de la asistencia social dentro del sistema sueco de seguridad de los ingresos se produjo en el contexto de la disminución de su eficacia para mitigar la pobreza.

Las prestaciones de asistencia social en 1990 eran, en promedio, más generosas en Suecia que en los Países Bajos, Alemania y el Reino Unido, no así en 2009, cuyas prestaciones disminuyeron con relación a estos tres países (Kuivalainen y Nelson, 2010:22). Derivado del insuficiente ajuste de los niveles de prestaciones al coste de la vida durante el periodo en cuestión, Suecia, luego de ser uno de los pocos países europeos con prestaciones de asistencia social por encima del umbral de riesgo de pobreza (es decir, por debajo de 60 por ciento de la media), se unió a los demás países europeos con prestaciones por debajo de ese nivel (Kuivalainen y Nelson, 2010:22).

Aunado a la tendencia general a la disminución de la generosidad, la protección de los ingresos contra el desempleo se supeditó a la búsqueda de empleo, con un seguimiento constante de los beneficiarios y la imposición de sanciones en caso de incumplimiento de las normas de elegibilidad. El reciente Modelo Sueco evoca a los disciplinarios programas de trabajo introducidos originalmente en los países anglosajones, que después se aplicaron en el contexto europeo (Peck, 2001; Lødemel y Trickey, 2001; Schierup, Hansen y Castles, 2006). En vez de mejorar las competencias de los desempleados a través de la educación y la formación, la función de la política del mercado laboral ha optado por mantener a los presuntos dependientes del Estado de bienestar "activos» y dispuestos a aceptar cualquier empleo disponible, incluso aquellos para los que están sobrecualificados. La atención se ha centrado cada vez más en la mejora de las capacidades de auto promoción de los beneficiarios de prestaciones sociales desempleados, que tienden a ser considerados responsables de su reintegración en el mercado laboral, así como de su propia situación económica (Bengtsson, 2014). Este cambio normativo en la orientación de la política social marcó una interrupción y, hasta cierto punto, una inversión del proceso a largo plazo de aumento de la descomposición que caracterizó las fases anteriores de desarrollo del Modelo Sueco, el cual está en consonancia con la evolución política actual en la Unión Europea en su conjunto. Lo anterior también ha incluido una revisión radical impulsada por la austeridad del 
sistema de pensiones, que en el pasado se basaba en la solidaridad entre clases y en los derechos universales.

Los superávit presupuestarios, obtenidos gracias a los recortes en el gasto del Estado de bienestar, se han empleado para financiar una serie de desgravaciones y reducciones fiscales; los más beneficiados fueron los grupos de mayores ingresos. En realidad, desde la década de 1980, la contribución de las ganancias de capital y de los ingresos por opciones sobre acciones a los ingresos de las personas - ubicadas en la cúspide de la distribución - ha sido inigualable en la historia del país; si bien sigue un desarrollo similar al de Estados Unidos, lo hace de una manera más limitada (Roine y Waldenström, 2012). Entre las reformas tributarias que contribuyeron al aumento de la desigualdad, aparece en 2007 una forma de crédito al impuesto sobre la renta de las personas físicas (jobbskatteavdrag en sueco), misma que se ha quintuplicado a la fecha. Dado que las prestaciones sociales no pueden ceñirse a este crédito fiscal, su introducción ocasionó una ampliación de la diferencia de ingresos entre aquellos que trabajan y los que no lo hacen (Fritzell, Bacchus, Bäckman, Borg, Ferrarini y Nelson, 2014:647). ${ }^{5}$

La desigualdad de ingresos continuó aumentando luego del comienzo de la crisis financiera mundial. Según un informe de la Oficina de Estadística de Suecia, el país experimentó el mayor aumento de la renta disponible (+26 por ciento) entre los países del norte y occidente de Europa entre 2005 y 2010 (SCB, 2012:26). Durante este periodo el nivel de pobreza se mantuvo estable, alrededor de 6 por ciento para los individuos con empleo, pero incrementó de 26 a 36 por ciento entre los desempleados (SCB, 2012:38). Así, a finales de los 1990 no todos los grupos sociales se beneficiaron de la misma manera con relación a la mejora general de la situación económica del país y del aumento más reciente (incomparable en Europa septentrional y occidental), de un ingreso promedio derivado de la crisis financiera mundial. Los inmigrantes, particularmente los que arribaron en las dos últimas décadas, se vieron afectados por los recortes en el Estado de bienestar y el aumento de la desigualdad.

\footnotetext{
${ }^{5}$ Hasta mediados de la década de 1980 la expansión del Estado de bienestar sueco se asoció con una disminución constante de la desigualdad de ingresos, que alcanzó el nivel más bajo de la historia, con un coeficiente de Gini de alrededor de 0.200 (Björklund y Jäntti, 2011:31). Desde mediados de la década de 1980 en adelante, la reducción del Estado de bienestar invirtió la tendencia de larga duración de la disminución de la desigualdad. Así, desde mediados de los 1990, Suecia registró el aumento más rápido de la desigualdad de ingresos (en puntos porcentuales) entre los países de la OCDE, con un aumento de casi un tercio del coeficiente de Gini, desde mediados de los 1980 hasta 0.259 en 2008 (OCDE, 2011).
} 


\section{Las irregularidades de la desigualdad racializada}

Al igual que las políticas de otras áreas, el régimen de la política de inmigración se ha desarrollado como un elemento y parte integral del Modelo Sueco. Posterior a la mitad de los 1980, cuando este último comenzó a acumular problemas, la política de inmigración presentó síntomas de una crisis inminente referente a su capacidad para incorporar a nuevos inmigrantes (Ålund y Schierup, 1991; Schierup, Hansen y Castles, 2006). La crisis económica a principios de la década de 1990 y la subsecuente reestructuración del Estado de bienestar provocaron impactos negativos para la integración de inmigrantes. Los grupos más afectados a causa de estos acontecimientos fueron aquellos que llegaron como refugiados provenientes de países asolados por la guerra en Medio Oriente y los Balcanes. Cuando la crisis alcanzó su punto más álgido, Suecia registró el segundo lugar más alto de solicitudes de asilo per cápita en Europa (después de Suiza) procedentes de estas áreas geográficas, mismas que se mantuvieron como las principales fuentes de migración no laboral dentro del país, lo que culminó en la actual crisis de refugiados de Medio Oriente.

En el periodo comprendido de 1993 a 1995, el crecimiento del desempleo fue mayor entre los nacidos en el extranjero que entre los ciudadanos nativos. Así, la tasa global del desempleo abierto en Suecia (como un porcentaje de la fuerza laboral activa) mostró una abrupta ascensión, de 1.5 por ciento en 1989 incrementó a 8.2 por ciento en 1993. En contraposición, en el caso de los extranjeros, de 3.5 por ciento aumentó a 24 por ciento en el mismo periodo (SCB, 2004).

Incluso después de la total recuperación económica, posterior a la recesión, la brecha del empleo entre los nacidos en el extranjero y los nacidos en el país se posicionó en un nivel más alto en comparación con la etapa previa a la crisis (Schierup, Hansen y Castles, 2006; Bevelander, 2009). Pese a la mejora en el rendimiento laboral de inmigrantes provenientes del hemisferio sur desde 1998 hasta 2008, un estudio reciente evidenció que la diferencia relacionada con los nativos seguía siendo considerable y que era mayor para las mujeres (Bevelander, 2013). Por ejemplo, considerando a las mujeres por separado, la diferencia entre las procedentes de Irán y Vietnam fue 20 por ciento más alta, y en el caso de las de Somalia fue de 55 por ciento más alta que el promedio para las mujeres en general; en cuanto a los hombres, la diferencia fue de 10 por ciento para los provenientes de Turquía y 40 por ciento para los de Irak y Pakistán, en contraste con el promedio general. 
La tasa de empleo agregado de los nacidos en el extranjero es notoriamente más alta en Suecia que en otros países miembros de la OCDE (2015:83). En efecto, en su reporte más reciente, Migrant Integration Policy Index (MIPEX) ${ }^{6}$ categorizó a Suecia con el puntaje más alto en la integración de los inmigrantes dentro del mercado laboral de entre 38 países (la Unión Europea-28 más Noruega, Canadá, Corea del Sur, Nueva Zelanda, Estados Unidos, Japón, Suecia, Australia, Islandia y Turquía). Todavía más: el Estado de bienestar sueco parece tener un mayor éxito que los otros seis países comparables (Irán, Vietnam, Somalia, Turquía, Irak y Paquistán) al momento de intentar sacar a los inmigrantes de la pobreza (Sainsbury, 2012:121). La efectividad del Estado de bienestar en Suecia para reducir la pobreza se debe al alto grado de inclusión en las políticas sociales, pues los inmigrantes con residencia legal gozan de derechos sociales similares a los que poseen los ciudadanos nativos.

En este contexto, es posible argumentar que, en términos absolutos, los inmigrantes en Suecia poseen mejores oportunidades que sus contrapartes en otros países europeos. Al mismo tiempo, y según ciertos indicadores socioeconómicos, la diferencia en condiciones de vida entre los nativos parece ser peor en Suecia que en otros países donde la redistribución es baja. Este nivel comparativamente más alto de desigualdad interétnica indica con claridad un problema estructural del Estado de bienestar sueco al nivelar las oportunidades entre los migrantes y los no migrantes.

Se presume que los despidos de larga duración y la evaluación de la política del mercado laboral han provocado que grandes grupos de personas nacidas en el extranjero dependan cada vez más de los medios de subsistencia, de la asistencia del bienestar residual o de la baja tasa de desempleo, es decir, de la compensación por desempleo (discutido, entre otros, por Lundh, Bennich-Björkman, Ohlsson, Pedersen y Rooth, 2002:58ff). Aunque la proporción de hogares de extranjeros que recibían prestaciones del Estado de bienestar sujetas a condiciones de recursos ( $\sin$ incluir las pagas del seguro de desempleo) correspondía, en gran medida, a la media sueca en el decenio de 1970, en los 1990 la había superado con creces. A lo largo de la mitad de la década de 1990, las personas nacidas en la «antigua Yugoslavia», "Medio Oriente» y África recibieron pagos de la seguridad social (sujetas a condiciones de recursos) con una frecuencia 10 veces mayor que los 
suecos nativos (Vogel, 2002:54). ${ }^{7}$ Este fue un factor importante detrás de la ampliación de la brecha de pobreza entre nativos y extranjeros, puesto que sólo 20 por ciento de los nativos en edad de trabajar experimentó pobreza al menos una vez durante el periodo comprendido entre 1996 a 2007, comparado con 45 por ciento de inmigrantes (Obućina, 2014:8). Un estudio reciente estimó que, durante el lapso de 2007 a 2008, la diferencia porcentual en las tasas de pobreza entre inmigrantes extracomunitarios y nativos en Suecia ocupó el cuarto lugar (después de Bélgica, Finlandia e Irlanda) entre 16 países de la Unión Europea (Hooijer y Picot, 2015:9). La existencia de un mayor riesgo de pobreza para los inmigrantes se explica por medio de las barreras que enfrentan en el mercado laboral: «Ni siquiera el eficaz Estado de bienestar sueco puede compensar totalmente las graves desventajas a las que se enfrentan los inmigrantes en el mercado laboral» (Kesler, 2014:55).

El elevado número de inmigrantes entre los beneficiarios del Estado de bienestar y su menor acceso a la seguridad social vinculada con los ingresos dilucidan en parte su mayor tendencia a la pobreza. Como ya se comentó, a principios de la década de 1990 y en adelante, el periodo se caracterizó por un estancamiento o disminución de la generosidad de las prestaciones sociales. En consecuencia, las discrepancias reflejadas en los ingresos y en los niveles de pobreza aumentaron considerablemente entre las personas con y sin empleo, además los solicitantes de asilo recién llegados se encontraban en condiciones todavía más precarias. Quizá el indicador que brinda una idea más esclarecedora en torno de dichas «barreras estructurales» es el grado de exclusión de los extranjeros del mercado laboral con relación a los nacidos en el país. De acuerdo con las últimas cifras de la OCDE, Suecia posee la mayor brecha de desempleo entre los nativos y los extranjeros de los 38 países que forman parte del conteo. Sólo Grecia, España y Bélgica ocuparon los primeros puestos (OCDE, 2015:89). Conforme a otro reporte realizado por Statistics Sweden, no obstante que Suecia es el tercer país con la proporción más baja de desempleados de larga duración (seis meses o más) en el empleo total de la Unión Europea-28, también es el país con la mayor diferencia en el desempleo de larga duración entre nativos y extranjeros (SCB, 2013).

Simultáneamente, los inmigrantes que consiguen empleo se ubican a menudo en la parte inferior del mercado laboral y en puestos de trabajo mal remunerados que no están a la altura de sus cualidades y experiencia laboral antes de 
emigrar. Ese problema afecta en particular a los inmigrantes con estudios obtenidos fuera de Suecia, puesto que a menudo no se reconocen sus cédulas, de ahí que se sientan obligados a continuar estudiando (inclusive comenzar desde cero), o bien a aceptar trabajos para los que están sobrecualificados (Alatalo y Ostapenko, 2014). Existen numerosas pruebas empíricas sobre la presencia de mecanismos similares de exclusión aun contra los inmigrantes de la primera generación, quienes invirtieron específicamente en la adquisición de capital humano sueco (por ejemplo, a través de la educación a largo plazo), y contra los hijos de los inmigrantes nacidos en Suecia (Rydgren, 2004). En sí, ambos grupos tienden a verse obstaculizados por prácticas discriminatorias institucionales, que les impiden su ingreso en el «núcleo» protegido del mercado laboral.

Los cambios aludidos se han producido en el contexto del cambio general de un Estado de bienestar keynesiano que al comprometerse con el pleno empleo había logrado evitar la bifurcación del mercado laboral en sectores de salarios bajos y altos, a un Estado de consolidación neoliberal. Este último se caracteriza por unas tasas de desempleo más elevadas, en especial entre los inmigrantes y sus descendientes, pero también por la aparición de un mercado laboral secundario con salarios bajos, en el que los acuerdos de trabajo informal son cada vez más frecuentes. Los extranjeros están representados de manera excesiva en este mercado laboral secundario y, en particular, dentro de los sectores restauranteros, de limpieza, de transporte y del mantenimiento de industrias de servicios privados (Bredström, 2002; Slavnic y Urban, 2008; Gavanas, 2010; Urban, 2013). Acorde con la reciente tendencia a la reducción de impuestos, se introdujo una serie de recortes con el propósito de estimular la creación de empleo en algunas industrias $y$, de ese modo, crear oportunidades de empleo concebidas explícitamente como adecuadas para los inmigrantes desempleados. Las iniciativas incluyen la reducción del IVA en los servicios restauranteros y de catering en 2012 (Urban, 2013), además de la introducción de deducciones fiscales para los hogares que adquieran servicios domésticos o servicios de reparación de viviendas en 2007 (Nyberg, 2015).

El efecto simultáneo de las intervenciones del gobierno central por el lado de la oferta (con el cumplimiento de los requisitos de activación) y por el lado de la demanda (con reducciones de impuestos para la creación de empleo en servicios privados de baja cualificación) ha intensificado las desigualdades existentes en el mercado laboral sobre las líneas étnicas. Una parte cada vez mayor de extranjeros y de hijos de extranjeros carece de empleo y de asistencia social, incluso atraviesa por periodos de empleo intermitente en trabajos mal pagados, lo que significa que 
no tiene derecho a prestaciones de desempleo. Al respecto, el último informe de la Agencia Sueca para la Juventud y la Sociedad Civil (MUCF, 2016) mostró que las diferencias entre los jóvenes adultos nativos y los extranjeros se han agravado en todos los aspectos de la vida social, desde la educación hasta el mercado laboral, pasando también por la participación en actividades políticas o culturales.

En 2015, 90 por ciento de los estudiantes nativos del primer ciclo de secundaria tenía derecho de continuar en el segundo ciclo, mientras que el porcentaje correspondiente a los nacidos en el extranjero fue de 57 por ciento. Ese año la tasa de desempleo fue de 11 por ciento entre los nativos desde los 16 a los 24 años y de 35 por ciento entre los extranjeros del mismo grupo de edad. En adición, los extranjeros y su descendencia tienen menor posibilidad de ser políticamente activos que los nativos y los hijos de éstos (MUCF, 2016).

Así, para los inmigrantes y los grupos racializados, como argumenta Neergaard (2009:209-210), el paso de un régimen de pleno empleo a otro en el que el desempleo se convierte en una fuerza motriz para un reacondicionamiento disciplinario del trabajo denota, a la vez, pasar de la «inclusión subordinada» a la «exclusión subordinada». Vincula el trabajo racializado a un ejército de reserva que reduce los salarios y el trabajo precario en guetos ocupacionales de bajos salarios, lo que también se relaciona con un acceso inferior a la organización colectiva y a los recursos políticos. ${ }^{8}$

Desde los 1990, el aumento general de la desigualdad se ha visibilizado en el paisaje urbano sueco, mediante una creciente polarización socioespacial hacia la etnicidad y el ingreso de las ciudades (Scarpa, 2015a). Esta polarización social espacial se debe a los procesos de "gentrificación» $\mathrm{y}$ "filtrado» (Hedin, Clark, Lundholm y Malmberg, 2012). La gentrificación tomó la forma de «súper gentrificación", derivado de la entrada de hogares de altos ingresos en barrios ya ricos, dominados por viviendas unifamiliares ocupadas por sus propietarios. En contraposición, el filtrado de bajos ingresos involucró en especial a los barrios más pobres, dominados por las viviendas multifamiliares de alquiler, que experimentaron una nueva disminución del ingreso promedio.

${ }^{8}$ La noción de "gueto ocupacional» fue acuñada por Stephan Feuchtwang (1982) en un estudio de discriminación y racialización del mercado laboral del Reino Unido. 


\section{Una pequeña revolución: mantra y realidad de la «migración gestionada»}

Las reformas migratorias del año 2000 incluyeron nuevos aspectos en este proceso rumbo a la precariedad de trabajo, de sustento y de agravamiento de la inequidad racial. Una nueva ley sobre migración laboral, aprobada por el Parlamento en 2008 (Regeringen, 2008; Sveriges Riksdag, 2008), condicionó la duración de los permisos de residencia y, en última instancia, el acceso a la plena ciudadanía formal y a la duración de los contratos de trabajo. Su apertura a un régimen de trabajadores migrantes temporales, en principio ilimitado, impulsado por los empleadores, se ha caracterizado como una «revolución ligera» (Cerna, 2009) en un país con una estructura ramificada de larga data de ciudadanía sujeto a garantías democráticas, quizá más inclusivas que en cualquier otro lugar (Sainsbury, 2006). Los sindicatos temen que la dependencia de los nuevos inmigrantes temporales de determinados empleadores, aunado al peligro siempre latente de perder su empleo y su permiso de trabajo, conduzca a una postura de negociación muy débil y a la exposición de una explotación excesiva (Davidsson, 2008; Hjärtberg, 2008), misma que ha demostrado estar justificada (por ejemplo, en Calleman y Herzfeld, 2015).

En consecuencia, la ley de 2008 abrió un tercer estatus — desfavorecido y precario - junto a los ya establecidos estatus duales de ciudadano (pleno) y habitante. A través de su insistencia en hacer que la residencia dependa del estatus de empleo, la ley, en efecto, amplió el alcance del implacable incremento de dicha insistencia en una flexibilidad laboral disciplinaria; sin embargo, desplazó el cambio de la inclusión subordinada a la exclusión subordinada hacia el ámbito del control de la inmigración y hacia una ley de ciudadanía cada vez más discriminatoria. Así, Suecia se ha atrasado en las prácticas emergentes a escala europea de la llamada "migración gestionada», la cual se ha sometido a un control más estricto que los sistemas (alemanes, austriacos y suizos) de trabajadores invitados de Europa central (véase Guild, Carrera y Atger, 2009; Guiraudon, 1998). Étienne Balibar (2004) considera esto como un emergente apartheid europeo legalmente sancionado. Garantiza a los empleadores el acceso a largo plazo a una mano de obra mundial abundante, barata y fácilmente desechable, excluida de los privilegios de la ciudadanía, aunque a la vez apacigua a la extrema derecha y asegura que sólo unos pocos de esos nuevos trabajadores precarios tendrán acceso a la plena ciudadanía y a la pertenencia a la nación. 


\section{Una carrera hacia el fondo}

Se trata de un desarrollo de la precarización y de la cooptación política de la extrema derecha que se ha extendido y profundizado en sintonía con el desarrollo de la actual «crisis de los refugiados». Se encuentra estrechamente entretejido con la lucha por el poder entre la izquierda y la derecha en un momento marcado por la agitación política, respecto a la «crisis de los refugiados» situada tácticamente como una estratagema colocada en el centro del debate político y el discurso de los medios de comunicación.

La alianza gobernante de centro-derecha perdió las elecciones generales suecas de 2014. Un gobierno minoritario de socialdemócratas y el Partido Verde Sueco (Miljöpartiet), con el apoyo parlamentario del Partido de Izquierda (Vänsterpartiet), tomaron el poder. Aun así, los extremos populistas racistas del Partido Demócrata Sueco (Sverigedemokraterna) mantuvieron un sólido equilibrio en el Parlamento y prometieron rechazar cualquier presupuesto general que no incluyera el cese de una política de asilo generosa, así como excluir la inmigración. Aunque a esto siguió el pánico político y el desorden, se evitó el colapso en diciembre de 2014 por un gran pacto de izquierda-derecha (Decemberöverenskommelsen) forjado de nuevo con el objetivo explícito de bloquear la influencia política del Partido Demócrata Sueco. Se suponía que el Pacto de Diciembre duraría dos periodos electorales consecutivos (ocho años). Sobre dicha base, el nuevo gobierno de izquierda-verde se atrevió a mostrar un presupuesto que proponía inversiones públicas relacionadas con una política de asilo liberal continua, así como inversiones generales en nuevas reformas del mercado de trabajo, la educación y la política de bienestar social que redujeran las modificaciones. Según Peo Hansen (2016), en un estudio crítico de la «crisis de la inmigración» en Europa, parecía que se avecinaba un nuevo «keynesianismo de los refugiados», en virtud del cual el gasto en la integración de los refugiados impulsaría el dinamismo económico y el crecimiento con la capacidad de invertir en reformas del Estado de bienestar en lugar de exigir una austeridad fiscal en aumento.

En principio, sostiene Hansen, ni Suecia ni Alemania sucumbieron a la «austeridad racial»; por el contrario, una medida inicialmente audaz para manejar la «crisis de los refugiados» mediante un aumento necesario en el gasto del sector público presentó la oportunidad para un «raro experimento de laboratorio keynesiano (...) Numerosos informes corroboran este panorama con (...) un impacto positivo del gasto relacionado con los refugiados en el crecimiento económico de 
la Unión Europea en general, y con un impacto más significativo a medio y largo plazos previsto para esos países» (Hansen, 2016:33). ${ }^{9}$ Lisa Pelling (2015a), en su informe Pasajes legales sobre el Mediterráneo, señala un escenario que sugiere una sinergia realista entre una política de inmigración y asilo abierta y liberal y un desarrollo económico y demográfico sostenible.

La viabilidad de este escenario se encuentra ampliamente respaldada por el impacto dinámico en las finanzas públicas suecas que la migración afectó durante todo el periodo posterior a la Segunda Guerra Mundial (Scocco y Andersson, 2015); no obstante, para que este efecto sea sostenible, sería crucial una interacción catalítica entre dos niveles de políticas públicas (Scocco y Andersson, 2015). La «pequeña política de integración», dirigida directamente a las políticas de migración y a la incorporación de los recién llegados, y la "gran política de integración», que combina «una economía que funciona bien, con un alto nivel de empleo, un bajo nivel de desempleo, una adecuada provisión de vivienda en regiones con un mercado laboral fuerte, junto con un sistema educativo óptimo caracterizado por su alta calidad y equidad», tendrían que fusionarse. Se trata de un espacio apoyado por un relevante estudio comparativo reciente que documenta una correlación positiva general entre regímenes de bienestar sólidos y políticas generosas de asilo (Boräng, 2013).

En efecto, la ventana de oportunidad para un escenario de integración keynesiana impulsado por la inmigración se cerró abruptamente en Alemania, Suecia y la Unión Europea. En los casos de Alemania y Suecia, de acuerdo con Hansen (2016), "los intentos de explicar esto con un simple ceder a una austeridad racial al estilo de Dinamarca o Hungría» son insatisfactorios. El «cambio abrupto", aclara, "de una política de sbienvenidas a una de rechazo, y de una política que designa a los refugiados como una necesidad demográfico-económica a una que califica a los refugiados como un peligro social», precisa una explicación más compleja. "Para desafiar la austeridad de los refugiados en la Unión Europea actual, se requiere también desafiar su régimen maestro de austeridad fiscal de la Unión Europea. De lo contrario, la primera sólo llegará hasta donde la segunda lo permita» (Hansen, 2016:29-30). Tal argumento apunta a la persistente dinámica regresiva de la eurozona; empero, es necesario matizarlo más en cuanto a las condiciones y relaciones de poder diferenciales en las luchas por la hegemonía en Alemania en comparación con Suecia. Alemania

\footnotetext{
${ }^{9}$ Véase, entre otros, Fondo Monetario Internacional (2016) y Statistics Sweden (SCB, 2016).
} 
es el cerebro y el ferviente guardián del austero régimen financiero de la eurozona, cuyas normas no vinculan, en principio, a Suecia como país no miembro. En esta última, un partido populista de extrema derecha mantiene el equilibrio en el Parlamento, hecho que no sucede en Alemania. En la década de 2010, Suecia registró un enorme superávit en sus finanzas públicas, de modo que el país pudo haber tenido condiciones extremadamente favorables para un préstamo público barato. Tenía una capacidad económica real para, potencialmente, hacer grandes inversiones públicas en infraestructura, vivienda, educación, y para incluir un amplio y sostenido «keynesianismo de refugiados» con el pleno empleo como objetivo principal.

Originalmente, la austeridad fiscal fue instituida en Suecia en un momento de profunda recesión por un gobierno socialdemócrata, aunque en la actualidad es muy cuestionada por amplios sectores de la circunscripción electoral del partido y por un movimiento sindical todavía poderoso. Incluso, diversas medidas adoptadas por el gobierno de la minoría de izquierda-verde después de 2014 han comenzado a sondear la austeridad fiscal. El desmantelamiento del sector público en las últimas décadas, las reformas fiscales perturbadoras y las políticas que forjan un mercado laboral cada vez más precario con salarios bajos y un desempleo sustancial que garantiza que «la moral» y la disciplina son muestra de ello. Casi cualquier iniciativa en este sentido ha provocado reacciones vehementes por parte de la derecha parlamentaria, que es la potencialmente capaz de bloquear cualquier moción a través de una alianza encubierta con el Partido Demócrata Sueco. Dicho partido, por su parte, está dispuesto a apoyar cualquier moción parlamentaria a cambio de que se detenga la inmigración. Por ende, consideramos que el mantenimiento de un régimen de austeridad fiscal estricto está políticamente sobredeterminado por una coalición inminente entre la extrema derecha racista-populista (el Partido Demócrata Sueco) y la corriente principal de la derecha neoliberal.

Tras un aparente flujo de votos en encuestas de opinión consecutivas del mayor partido del bloque conservador (Moderaterna) al Partido Demócrata Sueco, y una rebelión dentro de las filas de la oposición de centro-derecha, el táctico Pacto de Diciembre se derrumbó después de sólo nueve meses. Destaca como un funesto momento de crisis cuando la derecha neoliberal llegó a la conclusión de que para reparar su hegemonía requeriría revitalizar sus propias raíces nacionalistas conservadoras y cooptar a la extrema derecha populista y racista en expansión. Sugiere un escenario de austeridad racial de color azul marrón antes de la Segunda Guerra Mundial, pero con características novedosas. 
Pese a lo anterior, este nuevo intento de hegemonía de la derecha parlamentaria sólo se convirtió en la obertura a un cínico y más amplio «juego de tronos» que de inmediato engulló a toda la política nacional; se trató de una carrera hacia el fondo en una competencia regresiva por la apropiación pragmática de los fundamentos de la agenda de la extrema derecha entre los dos grandes bloques políticos. De manera externa a estos dos bloques, por un lado, el Partido Demócrata Sueco celebró este desarrollo; por el otro, el Partido de Izquierda (Vänsterpartiet) aislado en defensa de la anterior política liberal de refugiados..$^{10} \mathrm{La}$ caída del Pacto de Diciembre de 2015 de la izquierda-derecha fue seguida por el nuevo pacto, fundamentalmente alterado, de derecha-izquierda en octubre de ese mismo año. Se convirtió en el consenso global antipopulista, que había sido la base principal para incorporar la política de inmigración, asilo e integración en el Estado de bienestar sueco, en su imagen reflejada, para la concesión - y una legitimación implícita - de la extrema derecha populista. Incluye, asimismo, la venta barata de normas y promesas electorales por parte de la coalición gubernamental rojiverde, lo que da lugar a reivindicaciones de larga duración de la derecha política sobre la reestructuración del mercado laboral.

En noviembre de 2015, el gobierno de la minoría roji-verde decidió negar la admisión de refugiados y reducir el ingreso a la cuota mínima impuesta por la Unión Europea. Se restablecieron los controles de identidad en la frontera con Dinamarca, lo que supuso una ruptura de facto con la Convención de Ginebra de 1951 relativa a los refugiados, así como una interrupción parcial de la pertenencia del país a Schengen. La trata de refugiados se ha convertido en un delito cada vez más frecuente, incluyendo a las personas que ayudan a los refugiados con un fin obviamente humanitario. De un solo golpe, el pacto político de centroderecha-izquierda reformado ${ }^{11}$ desmanteló los principios cardinales que durante décadas habían funcionado como garantía de solidaridad social y como pilar de la base del Modelo Sueco. ${ }^{12}$

El principio central de los permisos de residencia permanente como método previsor para la integración social y laboral de los refugiados se ha sacrificado con el objetivo de hacer de la concesión de la residencia temporal a los solicitantes

${ }^{10}$ Con la complicidad del liberal Partido del Centro en el acuerdo, aunque tomando una postura algo distante y crítica.

${ }^{11}$ De nueva cuenta, con excepción del Partido de Izquierda.

${ }^{12}$ Manifestado con el objetivo de organizar una política «ordenada» de asilo y recepción de refugiados y de «reducir los costos crecientes» (véase Regeringskansliet, 2015). 
de asilo la norma esencial (con la intención manifiesta de disuadir a los refugiados de solicitar asilo en Suecia). ${ }^{13}$ Para la mayoría, la protección temporal significa un corto periodo de 13 meses — con tres años para sólo unos pocos que reciben protección debido al estatus otorgado por la Convención de las Naciones Unidas. Además, los refugiados con protección temporal carecen de derechos de unificación familiar. Estos derechos, que antes eran de los más liberales, ya se encontraban entre los más restrictivos de toda la Unión Europea (sin embargo, fueron reinstaurados en el otoño de 2018).

La única manera de convertir la protección temporal en residencia permanente es mediante la obtención de una renta imponible que se considere adecuada para la «autosuficiencia»; esto significaría garantizar el empleo rápidamente. En realidad, parece una extensión del axioma neoliberal de la «empleabilidad», impulsada por la austeridad, al ámbito de la política de refugiados y asilo. Ejerce una gran presión en los refugiados para que acepten de inmediato cualquier empleo disponible, sin esperar a la convalidación de sus cualificaciones profesionales ni aprender sueco, hecho que les permitiría solicitar trabajos más competentes (Pelling, 2015b). En todo caso, tiende a igualar la situación de los refugiados y la de los trabajadores migrantes temporales, que no cuentan con la seguridad de una ciudadanía extendida; reduce las oportunidades de perseguir un proyecto de integración y desarrollo profesional a largo plazo, en concreto con empleadores capaces de jugar la carta de la deportación en cualquier momento; complementariamente, pone en peligro las perspectivas de sindicalización y empoderamiento político.

Lo que distingue la situación de los refugiados como solicitantes de empleo de la de los trabajadores migrantes circulantes, y que los hace particularmente vulnerables, es que los empleadores deben (ante todo, aunque no siempre en la práctica) ofrecer a los trabajadores migrantes circulantes el salario, las condiciones de trabajo y la seguridad social según las normas estandarizadas de los convenios colectivos en cualquier rama pertinente. Ello, según el pacto reforzado de refugiados, no se aplica a los denominados «trabajos introductorios» (introduktionsjobb) para los solicitantes de asilo bajo protección temporal. Los coloca en una posición en la que es aún más probable que se vean expuestos a los caprichos de los empleadores más depredadores en los guetos ocupacionales de un mercado laboral

${ }^{13}$ Excepto los menores no acompañados, los refugiados en esquemas de reasentamiento y las familias con hijos. 
despiadado y étnicamente dividido. Esta exención de la cobertura de los convenios colectivos ha sido impensable hasta ahora en el contexto sueco. Representa una concesión de los socialdemócratas a las facciones más neoliberales de la alianza de centro-derecha y un duro golpe al Modelo Sueco. La percepción implícita de la protección temporal como un ejército de reserva precario de mano de obra para los sectores de bajos salarios se reafirmó al aceptar otra concesión de la izquierda y al constituirse en un asunto de gran peso para la derecha en el nuevo «Pacto para los Refugiados». Se trata entonces de ampliar el alcance de las exenciones fiscales para los servicios domésticos con el fin de estimular el empleo de los refugiados en ese gueto ocupacional de «inmigrantes» precarios con bajos salarios.

\section{¿Cuál crisis de solidaridad?}

Con referencia al argumento general discutido en la introducción de este trabajo, coincidimos en que el Modelo Sueco del Estado de bienestar, o lo que queda de él, sufre una crisis de solidaridad; no obstante, explicar esta crisis en términos de una «ecuación de diversidad y bienestar» negativa es cambiar el orden de las cosas. Es indispensable basarnos en el argumento inicial, alusivo a que los valores públicos están moldeados políticamente y mediados institucionalmente. La solidaridad social, en la que debe descansar todo régimen de bienestar universal, depende de si la política, las políticas y las prácticas institucionales refuerzan o debilitan los conflictos por la redistribución.

Nuestro argumento previo indica que dos décadas y media de políticas impulsadas por la austeridad y la fragmentación institucional del Estado de bienestar, al fin han logrado inclinar la balanza a favor de la primera (refuerzo de conflictos distributivos), dependiente de la creciente desigualdad y de la segregación social y etnorracial. La migración se ha convertido, en particular por la "gran diversidad» y la «crisis de refugiados», en un ariete ideológico en la lucha por la economía (Schierup y Ålund, 2011a). El discurso chauvinista del Partido Demócrata Sueco sobre el Estado de bienestar —opuesto al de los ciudadanos suecos «merecedores», que durante generaciones han destacado por haber "ganado» los derechos y los privilegios del Estado de bienestar, con la llegada de los migrantes, los supuestos privilegios sociales «inmerecidos» pretenden minar el Estado de bienestar- eventualmente se ha convertido en un juego político, adoptado por un amplio espectro político. Los partidos de centro-derecha y de centro-izquierda contienden en una 
carrera por superarse mutuamente en la defensa de la reducción de los derechos establecidos para los migrantes desde tiempo atrás en un juego imaginario de suma cero, relacionado con los recursos supuestamente escasos en un Estado de bienestar en crisis, en apariencia socavado por la inmigración.

No obstante, hemos demostrado que las capacidades de integración social del modelo de bienestar sueco estaban comprometidas, sin conexión alguna con la «inmigración» o «diversidad étnica», mucho antes del inicio de la reciente "crisis de refugiados». En consecuencia, no es la escala de inmigración ni la creciente «diversidad étnica» lo que amenaza con hacer insostenible al Estado de bienestar sueco. Es la política de austeridad y la reestructuración neoliberal de las instituciones públicas suecas, que durante las últimas décadas han debilitado la capacidad de un Estado de bienestar profundamente transmutado para ofrecer vías de incorporación emancipatorias y no discriminatorias a los inmigrantes recién llegados, así como a muchos otros, entre los que se encuentran los desfavorecidos de Suecia. Esto plantea la necesidad inmanente de enfrentar el desafío de reconstruir instituciones sostenibles para la solidaridad social. La interrogante aún está pendiente si, en el cínico juego de tronos en curso, el modelo sueco se perdiera finalmente, o si nosotros - bajo circunstancias en que el neoliberalismo sufre una crisis de legitimidad que se aproxima - consideráramos una tercera opción que pusiera a prueba los argumentos que muestran una correlación positiva entre regímenes de bienestar fuertes e inclusivos y una política de refugiados abierta y "generosa». Sería una política prometedora para mediar el postulado antagonismo de la migración y el Estado de bienestar a favor del renacimiento del estilo keynesiano por una solidaridad más inclusiva con la inmigración, vista como una locomotora poderosa.

\section{Agradecimientos}

Este trabajo fue escrito a principios de 2017 y contó con el apoyo financiero del Consejo Sueco de Investigación para la Salud, la Vida Laboral y el Bienestar (FORTE, por sus siglas en sueco) (número de subsidio 2006-1524). 


\section{Referencias}

Alatalo, Juha M. and Oksana V. Ostapenko (2014), "The Swedish system: the image cracking when taking a closer look», Geoforum, 53, pp. 82-83.

Alesina, Alberto y Edward L. Glaeser (2004), Fighting poverty in the US and Europe, Oxford, Oxford University Press.

Andersson, Jenny (2015), "A model of welfare capitalism? Perspectives on the Swedish model, then and now», en Jon Pierre (ed.), The Oxford handbook of Swedish politics, Oxford, Oxford University Press, pp 563-577.

Angelin, Anna, Håkan Johansson y Max Koch (2014), «Patterns of institutional change in minimum income protection in Sweden and Germany», Journal of International and Comparative Social Policy, 30(2), pp. 165-179.

Arbetslöshetskassornas Samorganisation (2015), «Rapport över kompensationsgrad vecka 6/2015».

Balibar, Étienne (2004), We, the people of Europe? Reflections on transnational citizenship, Princeton and Oxford, Princeton University Press.

Bengtsson, Mattias (2014), "Towards standby-ability: Swedish and Danish activation policies in flux», International Journal of Social Welfare, 23(1), pp. 54-70.

Bevelander, Pieter (2009), "The immigration and integration experience: the case of Sweden", Immigration Worldwide: Policies, Practicies, and Trends, pp. 286-302. (2013), Scandinavia's population groups originating from developing countries: change and integration, Nordic Council of Ministers.

Björklund, Anders y Markus Jäntti (2011), SNS Välfärdsrapport 2011. Inkomstfördelningen i Sverige, Stockholm, SNS Förlag.

Boräng, Frida (2013), National institutions-international migration. Labour markets, welfare states and immigration policy, Gothenburg, Department of Political Science-Gothenburg University.

Bredström, Anna (2002), «Maskulinitet och kamp om nationella arenor. Reflektioner kring bilden av invandrarkillar i svensk media», en Paulina de los Reyes, Irene Molina y Diana Mulinari (eds.) Maktens (o)lika förklädnader. Kön, klass och etnicitet $i$ det postkoloniala Sverige, Stockholm, Atlas.

Calleman, Catharina y Petra Herzfeld Olsson (2015), Arbetskraft fran hela världen. Hur blev det med 2008 ars reform?, Stockholm, Statens Offentliga Utredningar, en https://vimeo.com/149006506

Cerna, Lucie (2009), Changes in Swedish labour immigration policy: a slight revolution?, Stockholm, SULCIS. 
Dahlberg, Matz, Karin Edmark y Heléne Lundqvist (2012), «Ethnic diversity and preferences for redistribution", Journal of Political Economy, 120(1), pp. 41-76.

Davidsson, Mattias (12 de noviembre de 2008), «Nya regler för arbetskraftsinvandring», Lag \& Avtal.

Eger, Maureen A. (2010), «Even in Sweden: the effect of immigration on support for welfare state spending», European Sociological Review, 26(2), pp. 203-217.

European Commission's Expert Group on Gender and Employment (EGGE) (2009), Gender segregation in the labour market. Root causes, implications and policy responses in the EU, Lithuania, EGGE.

Englund, P. (1999), «The Swedish banking crisis: roots and consequences», Oxford Review of Economic Policy, 15(3), pp. 80-97.

Esping-Andersen, Gøsta (1990), The three worlds of welfare capitalism, Oxford, Polity Press.

Feuchtwang, Stephan (1982), "Occupational ghettos», Economy and Society, 11(3), pp. 251-291.

Finseraas, Henning (2012), "Anti-immigration attitudes, support for redistribution and party choice in Europe», en Jon Kvist et al. (eds.), Changing social equality. The Nordic welfare model in the 21st Century, Chicago, University of Chicago Press, pp. 23-44.

Franzén, Elsie (2001), «Socialbidrag bland invandrare: erfarenheter från Sverige», Sociologisk Forskning (3-4), pp. 9-39.

Fritzell, Johan, Jennie Bacchus Hertzman, Olof Bäckman, Ida Borg, Tommy Ferrarini y Kenneth Nelson (2014), «Sweden: increasing income inequalities and changing social relations», en Brian Nolan et al. (eds.), Changing inequalities and societal impacts in rich countries. Thirty countries' experiences, Oxford, Oxford University Press, pp. 641-665.

Gavanas, Anna (2010), Who cleans the welfare state? Migration, informalization, social exclusion and domestic services in Stockholm, Stockholm, Institute for Future Studies.

Guild, Elspeth, Sergio Carrera y Anaïs Faure Atger (2009), Challenges and prospects for the $E U^{\prime}$ s area of freedom, security and justice: recommendations to the European Commission for the Stockholm Programme, Brussels, Centre for European Policy Studies, en http:// aei.pitt.edu/10762/01/1830.pdf.

Guiraudon, Virginie (1998), "Third country nationals and European law: obstacles to rights' expansion», Journal of Ethnic and Migration Studies, 24(4), pp. 657-674. 
Haffert, Lukas y Philip Mehrtens (2015), «From austerity to expansion? Consolidation, budget surpluses, and the decline of fiscal capacity», Politics \& Society, 43(1), pp. 119-148.

Hammar, Thomas (1990), Democracy and the Nation-State: aliens denizens and citizens in a World of International Migration, Aldershot, Avebury.

Hansen, Peo (2016), "Refugee keynesianism? EU migration crises in times of fiscal austerity», en Stefan Jonsson y Julia Willén (eds.), Austere histories in European societies: social exclusion and the contest of colonial memories, London, Routledge, pp. 135-160.

Hedin, Karin, Eric Clark, Emma Lundholm y Gunnar Malmberg (2012), «Neoliberalization of housing in Sweden: gentrification, filtering, and social polarization», Annals of the Association of American Geographers, 102(2), pp. 443-463.

Hjärtberg, Erik (13 de noviembre de 2008), «Kommunal kritiska till en ny lag om arbetskraftsinvandring», Kommunalarbetaren.

Hooijer, Gerda y Georg Picot (2015), «European welfare states and migrant moverty the institutional determinants of disadvantage», Comparative Political Studies, 48(14), pp. 1879-1904.

International Monetary Found (IMF) (2016), The refugee surge in Europe: economic challenges, IMF Staff Discussion.

Inspektionen för Socialförsäkringen (2013), «Personer som uppnår maximal tid i sjukförsäkringen. Vilka är de och vad händer efteråt?», Swedish Social Insurance Inspectorate.

Kesler, Christel (2014), «Welfare states and immigrant poverty Germany, Sweden and the United Kingdom in comparative perspective», Acta Sociologica.

Kjellberg, Anders (2011), "The decline in Swedish union density since 2007», Nordic Journal of Working Life Studies, 1(1), pp. 67-93.

Koopmans, Ruud (2010), "Trade-offs between equality and difference: immigrant integration, multiculturalism and the welfare state in cross-national perspective», Journal of Ethnic and Migration Studies, 36(1), pp. 1-26.

Kuivalainen, Susan y Kenneth Nelson (2010), The Nordic welfare model in a European perspective, Stockholm, Institute for future studies.

Kymlicka, Will y Keith G. Banting (2006), "Immigration, multiculturalism and the welfare state», Ethics \& International Affairs, 20(3), pp. 281-304.

Larsen, Christian Albrekt (2011), «Ethnic heterogeneity and public support for welfare: is the American experience replicated in Britain, Sweden and Denmark?», Scandinavian Political Studies, 34(4), pp. 332-353. 
Lentin, Alana y Gavin Titley (2011), The crises of multiculturalism: racism in a neoliberal age, United States, Zed Books.

Lundh, Christer, Li Bennich-Björkman, Rolf Ohlsson, Peder J. Pedersen y Dan-Olof Rooth (2002), Arbete? Var god dröj! Invandrare in välfärdssamhället, Stockholm, SNS.

Lødemel, Ivary Heather Trickey (2001), "An offer you can't refuse»: workfare in international perspective, United States, Policy Press.

Mau, Steffen y Christoph Bukhardt (29-30 de noviembre de 2007), "Ethnic diversity and welfare state solidarity in Europe», AGF midpoint Conference, Berlin.

MUCF (2016), Ung idag 2016. En beskrivning av ungas levnadsvillkor, Stockholm, Myndigheten för ungdoms-och civilsamhällesfrågor.

Mulinari, Diana y Anders Neergaard (2005), «A ‘black skull consciousness. Narratives of the new Swedish working class», Race \& Class, 46(3), pp. 55-71.

Neergaard, Anders (2009), «Racialisation in the labour market: in search of a theoretical understanding», en Anders Neergaard (ed.), European perspectives on exclusion and subordination: the political economy of migration, Maastricht, Shaker Publishing, pp. 201-222.

Nyberg, Anita (2015), «The Swedish RUT reduction. Subsidy of formal employment or of high-income earners' leisure time?», en Clément Carbonnier y Nathalie Morel (eds.), The political economy of household services in Europe, Springer, Palgrave Macmillan, pp. 221-241.

Obuina, Ognjen (2014), «Paths into and out of poverty among immigrants in Sweden», Acta Sociologica, 57(1), pp. 5-23.

OECD (2011), Divided we stand: why inequality keeps rising, Paris, OECD, en http://www. oecd.org/els/soc/dividedwestandwhyinequalitykeepsrising.htm

OECD (2015), «Indicators of immigrant integration 2015: settling in», Paris, OECD publishing.

Palme, Joakim, Tommy Ferrarini, Ola Sjöberg y Kenneth Nelson (2012), Sveriges socialförsäkringar i jämförande perspektiv En institutionell analys av sjuk-, arbetsskade-och arbetslöshetsförsäkringarna i 18 OECD-länder 1930 till 2010, Stockholm, Uppsala University/Department of Economics.

Peck, Jamie (2001), Workfare States, Washington, ERIC/IES, en https://eric.ed. gov/? id=ED461763

Pelling, Lisa (2015a), Lagliga vägar över Medelhavet. En färdplan, Stockholm, Arena Idé, en http://www.arenaide.se/rapporter/lagliga-vagar-over-medelhavet/ 
Pelling, Lisa (2015b), «Fristad Sverige? Om skyddssökande arbetskraftsinvandrares villkor», en Catharina Calleman y Petra Herzfeld Olsson (eds.), Arbetskraft frän hela världen. Hur blev det med 2008 airs reform?, Stockholm, DELMI, pp. 244-289.

Persson, Gunnar (1972), «Invandrarna och arbetarklassen i Sverige», Zenit, 27, pp. 4-14. Raneke, Andreas (2013), «Vart femte barn har utländsk bakgrund», SCB (Statistics Sweden), en http://www.scb.se/sv_/Hitta-statistik/Artiklar/Vart-femte-barn-har-utlandsk -bakgrund/

Rauhut, Daniel (2010), «Integration of Immigrants in Sweden 1945-1975», Finnish Yearbook of Population Research, 45, pp. 103-122.

Regeringen (2008), «New rules for labour immigration», Government Offices of Sweden, en http://www.regeringen.se/content/1/c6/10/72/00/2a13eb93.pdf.

Regeringskansliet (2015), «Insatser med anledning av flyktingkrisen», Regeringskansliet, en http://www.regeringen.se/informationsmaterial/2015/10/insatser-med-anled ning-av-flyktingkrisen/

Roine, Jesper y Daniel Waldenström (2012), "On the role of capital gains in Swedish income inequality», Review of Income and Wealth, 58(3), pp. 569-587.

Rueda, David y Jonas Pontusson (2000), «Wage inequality and varieties of capitalism», World Politics, 52(03), pp. 350-383.

Rydgren, Jens (2004), «Mechanisms of exclusion: ethnic discrimination in the Swedish labour market», Journal of Ethnic and Migration Studies, 30(4), pp. 697-717.

Ryner, Magnus (2000), "European welfare state transformation and migration», en Michael Bommes y Andrew Geddes (eds.), Immigration and welfare. Challenging the borders of the welfare state, London and New York, Routledge.

(2002), Capitalist restructuring, globalization and the third way: lessons from the Swedish model, Abingdon, Routledge.

Sainsbury, Diane (2006), "Immigrants' social rights in comparative perspective: welfare regimes, forms in immigration and immigration policy regimes», Journal of European Social Policy, 16(229), pp. 229-243.

(2012), Welfare states and immigrant rights: the politics of inclusion and exclusion, Oxford, Oxford University Press.

Scarpa, Simone (2013), «New geographically differentiated configurations of social risks: labour market policy developments in Sweden and Finland», en Ivan Harsløf y Rickard Ulmestig (eds.), Changing social risks and social policy responses in the Nordic welfare states, Springer, Palgrave Macmillan, pp. 220-244.

(2015a), The spatial manifestation of inequality, Växjö, Department of Social Work/Linneaus University. 
(2015b), "The Swedish model during the international financial crisis: institutional resilience or structural change?», en Gabriella Punziano (ed.), The European social model adrift: Europe, social cohesion and the economic crisis, Ashgate Publishing, pp. 107-126.

SCB (2004), «Sysselsättning och arbetslöshet 1975-2003», Statistics Sweden, en http:// www.ssd.scb.se/databaser/makro/start.asp

(2012), Levnadsstandard i Europa. Levnadsförhallanden, report no. 124, Stockholm, Statistics Sweden.

(2013), Arbetskraftsundersökningarna (AKU) tredje kvartalet 2013. Tema: Risker för langtidsarbetslöshet, Stockholm, Statistics Sweden.

(2016), Sveriges ekonomi, Stockholm, Statistics Sweden.

Schierup, Carl-Ulrik y Sven Paulson (1994), Arbetets etniska delning. Studier frän en svensk bilfabrik, Stockholm, Carlssons.

Schierup, Carl-Ulrik y Aleksandra Ålund (2011a), «The end of Swedish exceptionalism? Citizenship, neo-liberalism and politics of exclusion», Race \& Class, 53(1), pp. 45-64.

(2011b), «From paradoxes of multiculturalism to paradoxes of liberalism», Journal for Critical Education Policy Studies, 9(2), en http://www.jceps.com/?.pageID $=$ article\&article $\mathrm{ID}=228$

Schierup, Carl-Ulrik, Peo Hansen y Stephen Castles (2006), Migration, citizenship and the European welfare state. A European dilemma, Oxford, Oxford University Press.

Scocco, Sandro y Lars Fredrik Andersson (2015), 900 Miljarder skäl att uppskatta invandring. En analys av invandringens effekter på de offentliga finanserna $i$ Sverige 1950-2014, Stockholm, Arena Idé.

Slavnic, Zoran y Susanne Urban (2008), «Socio-economic trends in the Swedish taxi sector. Deregulation, recommodification, ethnification», International Journal on Multicultural Societies, 10, pp. 76-94.

Stichnoth, Holger y Karine Van der Straeten (2013), «Ethnic diversity, public spending, and individual support for the welfare state: a review of the empirical literature», Journal of Economic Surveys, 27(2), pp. 364-389.

Streeck, Wolfgang (2014), Buying time: the delayed crisis of democratic capitalism, Berlin, Verso Books.

Streeck, Wolfgang (2015), The rise of the European consolidation state, MPIFG discussion paper no. 15/1, Cologne, Max Planck Institute for the Study of Societies, en https://wolfgangstreeck.com/2015/02/13/the-rise-of-the-european-consolida tion-state/ 
Swenson, Peter (1991), «Managing the managers: the Swedish employers. Confederation, labor scarcity and the suppression of labor market segmentation", Scandinavian Journal of History, 16(4), pp. 335-356.

Sveriges Riksdag (2008), «Nya regler för arbetskraftsinvandring», Justitie Departement, en http://www.riksdagen.se/Webbnav/index.aspx?nid=37\&dok_id=GV03147

Taylor-Gooby, Peter (2005), "Is the future American? Or, can left politics preserve European welfare states from erosion through «racial diversity?», Journal of Social Policy, 34(4), pp. 661-672.

Urban, Susanne (2013), «Restaurant work experience as stepping stone to the rest of labour market», Nordic Journal of Migration Research, 3(2), pp. 100-109.

Wagle, Udaya (2013), The heterogeneity link of the welfare state and redistribution, Berlin, Springer International Publishing.

Vogel, Joachim (2002), «Inkomst och fattigdom», en Mikael Hjerm Vogel y Sven-Erik Johansson (eds.), Integration till svensk välfärd? Om invandrares välfärd på 90-talet, Stockholm, Statistics Sweden/National Institute for Working Life, pp. 35-56.

Ålund, Aleksandra (1985), Skyddsmurar. Etnicitet och klass in invandrarsammanhang, Stockholm, Liber.

104

Ålund, Aleksandra y Carl-Ulrik Schierup (1991), Paradoxes of multiculturalism. Essays on Swedish society, Aldershot, Avebury, en http://liu.diva-portal.org/smash/record. jsf?pid= diva2:213706 